\title{
Synthesis and Thermotropic of PAMEs Based on 1-Phenethyl-4- Piperidone Moiety
}

\author{
ISMAIL A. Alkskas ${ }^{*}$, AMNA A. Abayo ${ }^{2}$ \\ 1Department of Chemistry, Faculty of Pharmacy, Misurata University, Misurata, Libya \\ 2Department of Chemistry, Faculty of Science, Misurata University, Misurata Libya
}

\section{*Corresponding Author: Ismail A. Alkskas, Alkskas122@yahoo.com}

\begin{abstract}
:
New poly(azomethine-ether)s PAMEs containing 1-phenethyl-4-piperidone moiety have been synthesized through a solution polymerization of various diformyl-a,w-diphenoxyalkanes, I-IV with 3,5-bis(p-aminobenzylidene)-1-Phenethyl-4-piperidone VI. The structures of these polymers were confirmed using spectroscopic techniques. The inherent viscosities of the resulting polymers were found to range from 0.65 to $0.95 \mathrm{dl} / \mathrm{g}$. The solubility of the PAMEs was estimated, showing good solubility in aprotic solvents. The thermal properties of the PAMEs were also evaluated by DSC technique. Liquid crystalline state of the polymers was observed on polarizing microscope exhibiting nematic phase for most of the synthesized polymers.
\end{abstract}

Keywords: PAMEs; Piperidone; Thermotropic; Texture observation

\section{Introduction}

Recently, liquid crystal polymers had become a well-known technology due to their wide range of applications such as electronic devices and super-strong materials ${ }^{[1-3]}$. There has been a great interest in liquid crystalline polymers that consist of a solid linear mesogeneic group and flexible methylene groups. In general, the mesogeneic groups and elastic modules were bound by the ether, ketone, ester or amide group ${ }^{[4-8]}$. There has been a significant progress in the development of thermotropic liquid crystalline polymers which have flexible units with linked azomethineether in order to lead to lower melting temperatures, more flexibility, improved solubility and enhanced specific properties such as misomorphism ${ }^{[9-13]}$. As mentioned in many scientific papers, transitional temperatures decrease with the presence of methylene groups where the elasticity of polymer depends on the number of methylene groups, but the solubility is still not satisfactory. An improvement in the solubility of the urinary PAMEs containing substituted groups such as alkyl and alkoxy groups has been reported ${ }^{[14-16]}$. The presence of a heterogeneous atom in the hydrocarbon rings of the polymer main chain such as a nitrogen and sulfur atom has a direct effect on the physical properties of polymer. Moreover it increases thermal stability and improves the solubility of the polymer as a mesogenic group ${ }^{[17-19]}$. The introduction of piperidone moiety as heterocyclic ring in the polymer back bone has an effect on the properties of the polymer. However, there are few reports related to the preparation of PAMEs containing heterocyclic rings ${ }^{[20-22]}$. The aim of this paper is to report on the preparation of a new PAMEs containing a heterocyclic ring of piperidone moiety and study of some properties such as solubility, thermal stability and thermotropic liquid crystal.

\section{Materials and Methods}

\subsection{Reagents and solvents}

4-Hydroxy-3-methoxybenzaldehyde, 1-phenethyl-4-piperidone and dihaloalkanes were purchased from (Aldrich) whereas 4-nitrobenzaldehyde was purchased from (Fluka) they were used without purification. Ethanol (95\%), and all other solvents were of a high purity however they were purified by standard methods ${ }^{[23]}$.

\subsection{Measurements}

Melting points of the synthesized samples were determined on an Electro thermal IA9100 melting point apparatus and are reported as such. The elemental composition was determined by Elementary Vario EL III instrument. The infrared spectra in the range $4000-650 \mathrm{~cm}^{-1}$ of solid samples of the synthesized monomers and polymers were obtained using a Cary 630 FTIR spectrophotometer. The ${ }^{1} \mathrm{H}-\mathrm{NMR}$ 
spectra were recorded on Varian a Gemini $200 \mathrm{MHz}$ NMR spectrophotometer at room temperature in DMSO solvent using TMS as the internal reference. Mass spectra were recorded on a Shimadzu Qp-2010 mass spectrometer. The inherent viscosities were measured using an Ubbelohde viscometer using a suspension in DMF at $25^{\circ} \mathrm{C}(0.5 \mathrm{dIg}-1)$. The thermal properties of the samples were investigated using Differential Scanning Calorimetry (DSC). The DSC recordings were carried out in inert nitrogen using a Shimadzu DSC-50 thermal analyzer. Liquid crystalline behavior was investigated by POM using an Optika B-1000 Polarizing Optical Microscope (POM) attached to a hot stage.

\subsection{Monomer synthesis}

4,4'-diformyl-2,2'-dimethoxy-a, $\omega$-diphenoxyalkanes I-IV were synthesized by reported method ${ }^{[15]}$.

2.1.1 3,5-Bis(p-nitrobenzylidene)-1-phenethyl-4-piperidone $(\mathrm{V})$

In a $150 \mathrm{ml}$ around-bottomed flask was disolved a mixture of 4-nitrobenzaldehyde $6.04 \mathrm{~g}(40 \mathrm{mmol})$ and of 1-phenethyl-4-piperidone $4.06 \mathrm{~g}(20 \mathrm{mmol})$ in $25 \mathrm{ml}$ ethanol while stirring at $50{ }^{\circ} \mathrm{C}$. A few drops of alcoholic potassium hydroxide were then added to the reaction mixture with a continuous stirring for a period of two hours where the yellow precipitate was formed. The desired product $\mathrm{V}$ was collected by filtration and recrystallized from ethanol, yield $80 \%, \mathrm{mp} 163{ }^{\circ} \mathrm{C}$. Anal Calcd for $\mathrm{C}_{27} \mathrm{H}_{23} \mathrm{~N}_{3} \mathrm{O}_{5}$ : C, 69.01; $\mathrm{H}, 4.93$; N,8,95\%. Found: C, 69.35; H, 4.61; N,8,34\%. IR $\left(\mathrm{cm}^{-1}\right) ; 2990$ ( $\mathrm{C}-\mathrm{H}$ aliphatic stretching); $1660(\mathrm{C}=\mathrm{O})$; $1600(\mathrm{C}=\mathrm{C}) ; 1340,1530\left(\mathrm{NO}_{2}\right)$ and 1435 (piperidone $\mathrm{C}-\mathrm{H}$ deformation). The mass spectrum showed molecular ion peak at $\mathrm{m} / \mathrm{z}=469(13.4 \%)$ in agreement with its molecular formula $\left(\mathrm{C}_{27} \mathrm{H}_{23} \mathrm{~N}_{3} \mathrm{O}_{5}\right)$, and other peaks appeared at, $\mathrm{m} / \mathrm{z}$ $=423\left(\mathrm{M}^{+}-\mathrm{NO}_{2}, 7.3 \%\right)$ and $\mathrm{m} / \mathrm{z}=364\left(\mathrm{M}^{+}-\mathrm{CH}_{2} \mathrm{CH}_{2} \mathrm{C}_{6} \mathrm{H}_{5}\right.$, 9.8\%). ${ }^{1} \mathrm{H}-\mathrm{NMR}$ (DMSO-d $\mathrm{ppm}$ ): 8.2 (s, $2 \mathrm{H}$ of $2 \mathrm{CH}=\mathrm{C}$ ), 7.9-7.7 (m, 8H of benzylidene), 7.1-7.0 (m, 5H of Ar-H ), 3.9 (s, $4 \mathrm{H}$ of methylene group of piperidone), $2.8(\mathrm{t} 2 \mathrm{H}$ of $\mathrm{CH} 2$ attached with phenyl group) and $2.6\left(\mathrm{t} 2 \mathrm{H}\right.$ of $\mathrm{CH}_{2}$ attached with $-\mathrm{N}=$ of piperidone) (figure 1 ).

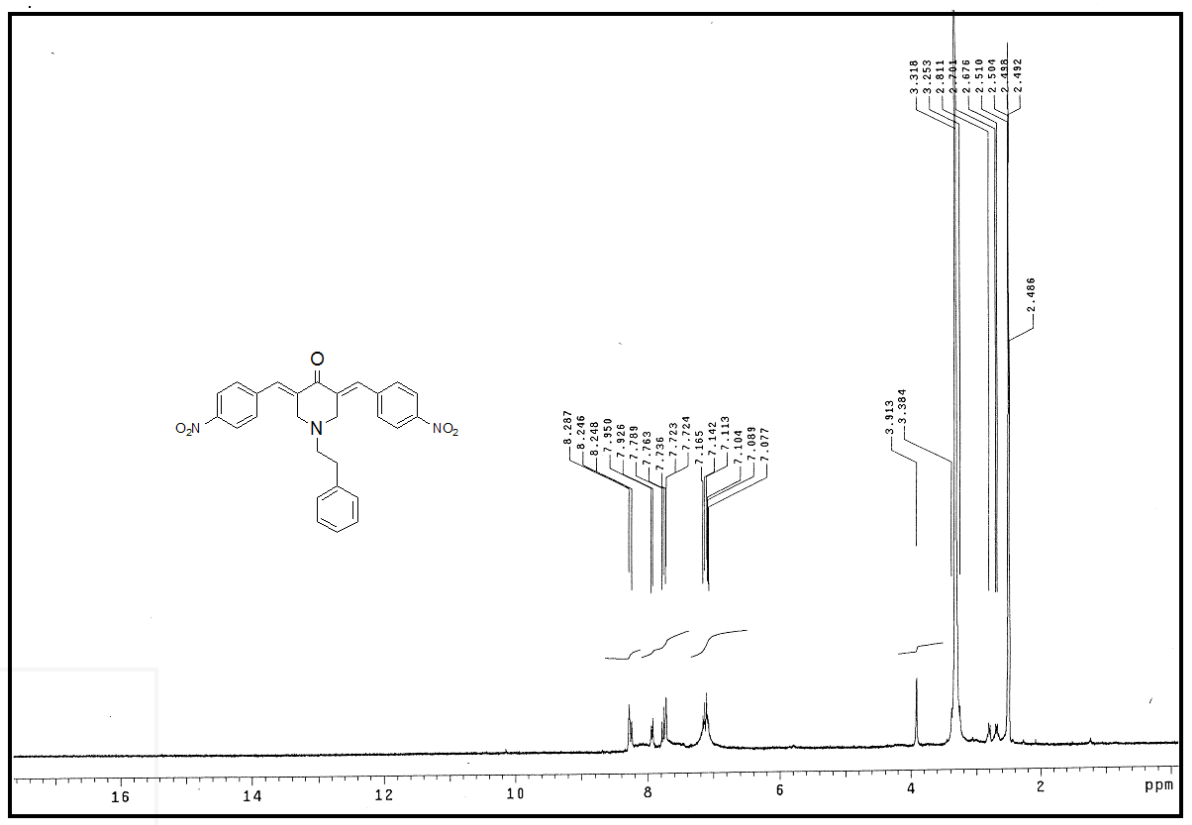

Figure $1{ }^{1} \mathrm{HNMR}$ spectrum of monomer V

\subsection{2. 3,5-Bis(p-aminobenzylidene)-1-phenethyl-4-} piperidone (VI)

A 3,5-Bis(p-nitrobenzylidene)-1-phenethyl-4-piperidone $3.99 \mathrm{~g}(8.52 \mathrm{mmol})$ was placed in a $100 \mathrm{ml}$ flask with $30 \mathrm{ml}$ of absolute ethanol and then the solid mixture was dissolved by warming it under stirred. A catalytic amount of $10 \%$ palladium on activated carbon was added to the mixture and hydrazine hydrate $(3 \mathrm{ml})$ diluted with absolute alcohol $(9 \mathrm{ml})$ was then in a drop wise to the mixture. The reaction mixture was kept at $50^{\circ} \mathrm{C}$ for two hours. The desired product VI was collected by filtration and recrystallized from ethanol, yield $80 \%, \mathrm{mp} 110^{\circ} \mathrm{C}$. Anal Calcd for $\mathrm{C}_{27} \mathrm{H}_{27} \mathrm{~N}_{3} \mathrm{O}$ : C, 79.10; H, 6; 65; N, 10.26\%. Found:
C, 79.50; H, 6.80; N, 10.19\%. IR (cm-1): 3390-3195 (NH stretching); 2850-2940 (C-H of piperidone); 1685 (C=O of piperidone); $1600(\mathrm{C}=\mathrm{C})$ and $680(\mathrm{NH}$ deformation). The mass spectrum showed molecular ion peak at $\mathrm{m} / \mathrm{z}$ $=409(10 \%)$ in agreement with its molecular formula $\left(\mathrm{C}_{27} \mathrm{H}_{27} \mathrm{~N}_{3} \mathrm{O}\right)$, and other peaks appeared at $\mathrm{m} / \mathrm{z}=304\left(\mathrm{M}^{+}-\right.$ ph- $\left.\mathrm{CH}_{2}-\mathrm{CH}_{2}, 54 \%\right)$ and at $\mathrm{m} / \mathrm{z}=303\left(\mathrm{M}^{+}-\mathrm{NH}_{2}-\mathrm{ph}-\mathrm{CH}_{2}\right.$, $52 \%) .{ }^{1} \mathrm{H}-\mathrm{NMR}$ (DMSO-d, $\left.\mathrm{ppm}\right):(\mathrm{s}, 2 \mathrm{H}$ of $2 \mathrm{CH}=\mathrm{C}), 7.9-$ 7.7 ( $\mathrm{m}, 8 \mathrm{H}$ of benzylidene), $5.2\left(\mathrm{~b}, 2 \mathrm{H}\right.$ of $\left.-\mathrm{NH}_{2}\right), 7.1-7.0(\mathrm{~m}$, $5 \mathrm{H}$ of $\mathrm{Ar}-\mathrm{H}$ ), 3.9 (s, $4 \mathrm{H}$ of methylene group of piperidone), $2.8\left(\mathrm{t} 2 \mathrm{H}\right.$ of $\mathrm{CH}_{2}$ attached with phenyl group) and $2.8(\mathrm{t} 2 \mathrm{H}$ of $\mathrm{CH}_{2}$ attached with $\mathrm{N}$ of piperidone) (figure 2). 


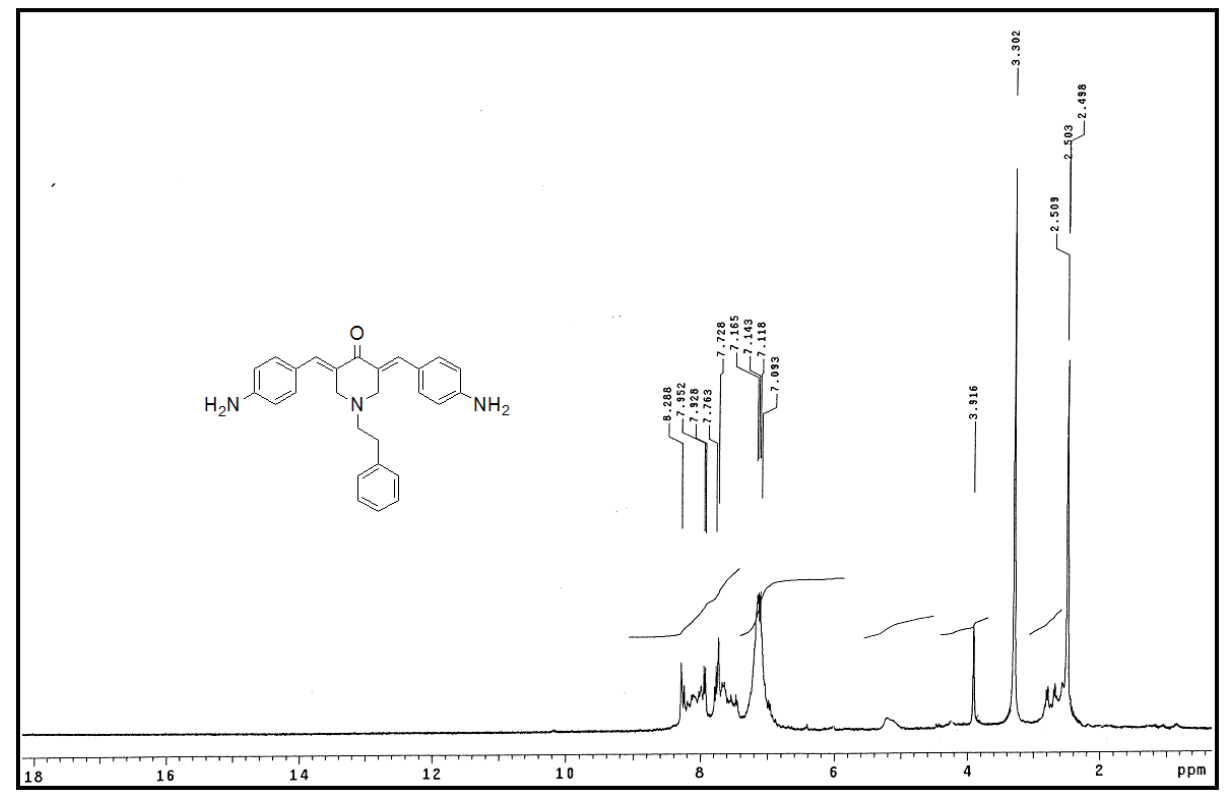

Figure $2{ }^{1} \mathrm{H}-\mathrm{NMR}$ spectrum of monomer VI

\subsection{Polymerization}

One polymer was used as a model for solution polymerization. The polymerization steps were carried out as follows: Bis-(p-aminobenzylidene)-1-phenithyl-4piperidone VI $(0.409 \mathrm{~g}, 1 \mathrm{mmol})$ was dissolved in absolute ethanol $(20 \mathrm{ml})$ and to this solution, the diformyl I was added $(0.358 \mathrm{~g}, 1 \mathrm{mmol})$ at $25^{\circ} \mathrm{C}$. The mixture was stirred at the same temperature for 20 minutes under nitrogen gas, then the stirring continued at $80^{\circ} \mathrm{C}$ for 3 hours. During this time, the viscosity of the polymer solution increased rapidly and samples were taken from the polymer solution during different time periods to confirm the polymerization by analyzing the infrared spectrum. The polymer began to appear as precipitate, the polymer was separated by filtration, washed with various organic solvents and then dried. The yield was $90 \%$.

\section{Results and Discussion}

The aim of this work is the preparation of new PAMEs VII $_{\mathrm{a}-\mathrm{d}}$ through solution polymerization of the 3,5-Bis(paminobenzylidene)-1-phenethyl-4-piperidone with various diformyl-a,w-diphenoxyalkanes I-IV. (Scheme1) formulates the methods used for the preparation of the dibenzylidene-1-phenethyl-4-piperidone. As shown, this compound was prepared by the base-catalyzed condensation of two moles of p-nitrobenzaldehyde with one mole of 1-phenethyl-4-piperidone followed by hydrogenation using palladium on activated carbon in ethanol at $50^{\circ} \mathrm{C}$. This method was used for the synthesis of PAMEs [14,16]. The expected structures of the resulting PAMEs VII ${ }_{\mathrm{a}-\mathrm{d}}$ were confirmed by elemental analyses and IR spectroscopy. The monomers used and the polymers are depicted in (Schemes 1 and 2).

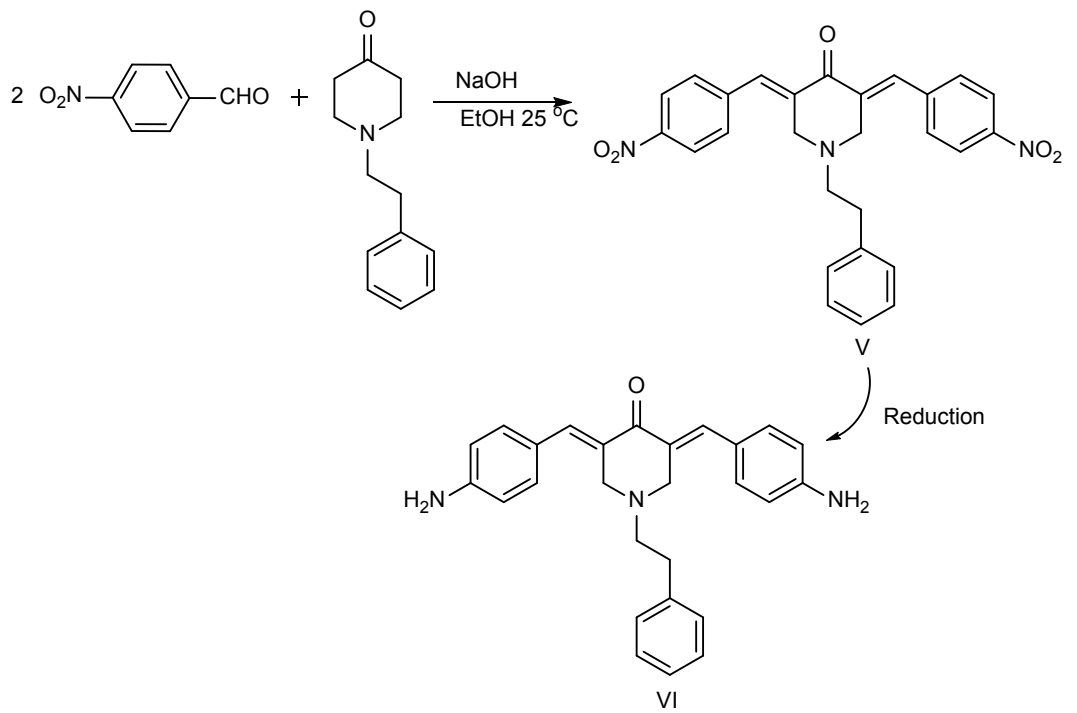

Scheme 1. Synthesis of Monomers V, VI. 
<smiles>[R]c1cc(C=O)ccc1OC(C)(C)CC(C)(C)Oc1ccc(C=O)cc1[R]</smiles><smiles>C#Cc1ccc(OC(C)(C)CC(C)(C)Oc2ccc(C=Nc3ccc(/C=C4\CN(CCc5ccccc5)C/C(=C\c5ccc(N=CC(C)C)cc5)C4=O)cc3)cc2OC)c(OC)c1</smiles>

Scheme 2 Synthesis of PAMEs VII ${ }_{\text {a-d }}$.

In this work, the polymerization reaction between a diamine monomer and a formyl monomer is usually done in ethanol to form relatively medium molecular weight. The reason for choosing ethanol is that the monomers dissolve easily and have a low boiling point. The polymers obtained have an inherent viscosity from 0.65 to $0.90 \mathrm{dl} / \mathrm{g}$ and can be easily obtained in high yields after a few minutes. The physical properties of these polymers are listed in (Table 1).

Table 1 Elemental analysis, yields and inherent viscosities of PAMEs VII

\begin{tabular}{|c|c|c|c|c|c|c|c|}
\hline $\begin{array}{l}\text { Polymer } \\
\text { number }\end{array}$ & $\begin{array}{c}\text { Yield } \\
(\%) \\
\end{array}$ & $\begin{array}{l}\eta_{\text {inh }}{ }^{a} \\
\text { dIg }^{-1} \\
\end{array}$ & $\begin{array}{l}\text { Molecular formula } \\
\text { (mol. wt) }\end{array}$ & & $\begin{array}{c}\text { Percen } \\
\text { C } \\
\end{array}$ & $\mathrm{H}$ & $\mathrm{N}$ \\
\hline \multirow{2}{*}{$\mathrm{VII}_{\mathrm{a}}$} & \multirow{2}{*}{90} & \multirow{2}{*}{0.83} & \multirow{2}{*}{$\begin{array}{c}\mathrm{C}_{47} \mathrm{H}_{45} \mathrm{~N}_{3} \mathrm{O}_{5} \\
(731)\end{array}$} & Calc. & 77.15 & 6.15 & 5.74 \\
\hline & & & & Found & 77.65 & 5.98 & 5.21 \\
\hline \multirow{2}{*}{$\mathrm{VII}_{\mathrm{b}}$} & \multirow{2}{*}{85} & \multirow{2}{*}{0.95} & \multirow{2}{*}{$\begin{array}{c}\mathrm{C}_{49} \mathrm{H}_{49} \mathrm{~N}_{3} \mathrm{O}_{5} \\
(759)\end{array}$} & Calc. & 77.47 & 6.45 & 5.53 \\
\hline & & & & Found & 77.87 & 6.10 & 5.70 \\
\hline \multirow{2}{*}{$\mathrm{VII}_{\mathrm{c}}$} & \multirow{2}{*}{85} & \multirow{2}{*}{0.76} & \multirow{2}{*}{$\begin{array}{c}\mathrm{C}_{51} \mathrm{H}_{53} \mathrm{~N}_{3} \mathrm{O}_{5} \\
(787)\end{array}$} & Calc. & 77.76 & 6.73 & 5.33 \\
\hline & & & & Found & 77.12 & 6.11 & 5.42 \\
\hline \multirow{2}{*}{$\mathrm{VII}_{\mathrm{d}}$} & \multirow{2}{*}{84} & \multirow{2}{*}{0.65} & \multirow{2}{*}{$\begin{array}{c}\mathrm{C}_{53} \mathrm{H}_{57} \mathrm{~N}_{3} \mathrm{O}_{5} \\
(815)\end{array}$} & Calc. & 78.03 & 6.99 & 5.15 \\
\hline & & & & Found & 77.89 & 6.50 & 4.91 \\
\hline
\end{tabular}

${ }^{\text {a }}$ Measured for solutions in DMF, with $\mathrm{C}=0.5 \mathrm{dIg}^{-1}$ at $25^{\circ} \mathrm{C}$

The infrared spectrum was used to confirm the structure of these polymers which containing the azomethine-ether unit. The infrared spectra of all prepared polymers indicate the disappearance of the absorption band of the amino group at $3300 \mathrm{~cm}^{-1}$, new absorption bands have also appeared at $1660 \mathrm{~cm}^{-1}$ for the azomethine

groups in addition to the appearance of the distinctive absorption band due to $\mathrm{CH}$ stretching of methylene groups at $2940-2860 \mathrm{~cm}^{-1}$. The absorption band of carbonyl group of piperidone ring occurred at $1670-1685 \mathrm{~cm}^{-1} ; \mathrm{C}=\mathrm{C}$ at $1620-1625 \mathrm{~cm}^{-1}$ and $\mathrm{C}-\mathrm{O}-\mathrm{C}$ bonds (ether linkages), at 1230 $1275 \mathrm{~cm}^{-1}$ (figure 3 ).

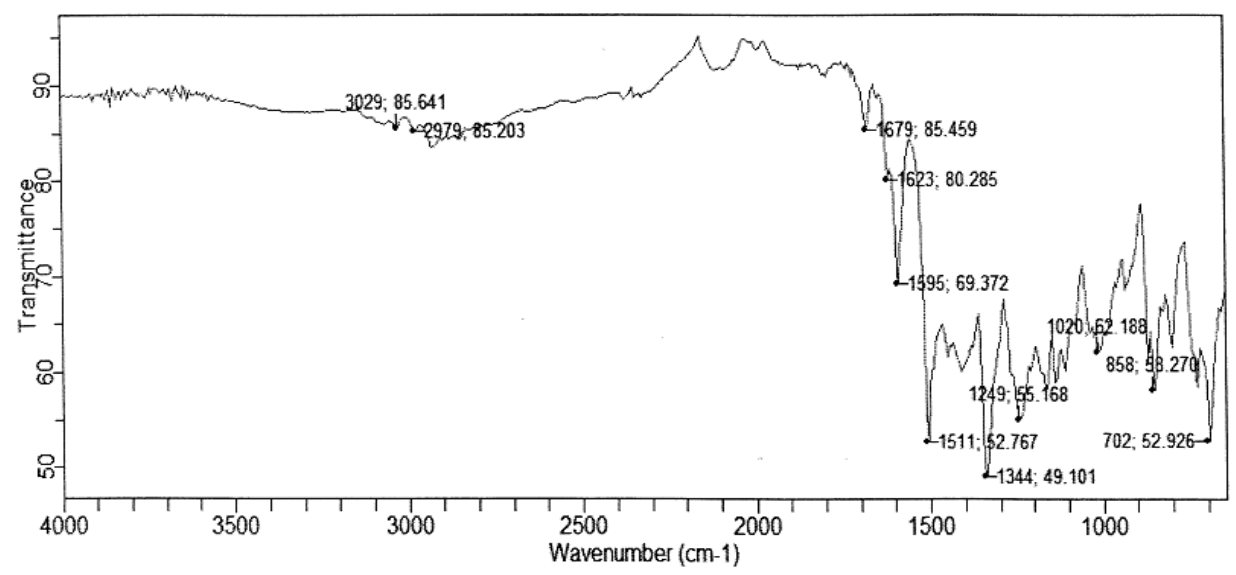

Figure 3 IR spectrum of polymer VII 


\subsection{Polymer characterization}

The solubility properties of the prepared PAMEs in various solvents at room temperature are shown in (Table 2). It was noted that all PAMEs dissolve easily in concentrated sulfuric acid that can be attributed to the decomposition of the polymer core. These polymers were completely dissolved in aprotic solvents such as dimethylsulfoxide and $\mathrm{N}$-dimethylformamide. The good solubility of these PAMEs may be due to the loose packing of the polymer construction with the 1-phenethyl-4-piperidone ring as a pendent group ${ }^{[18]}$. Among halogenated solvents such as methylene chloride and chloroform, all PAMEs were found to be partially soluble in methylene chloride and insoluble with the rest of the halogenated solvents. Moreover, as for the common organic solvents such as methanol and benzene, these PAMEs were insoluble. Comparing the solubility of PAMEs containing cycloalkanone moiety ${ }^{[16]}$ with those containing piperidone ring, it was found that the former possessed less solubility than the latter. This may be due to the effect of the phenethyl moiety as a pendent group in which the polymer chains are far from each other, allowing the solvent to penetrate between the polymer chains. Therefore, the presence of the piperidone ring with the phenethyl group increases the solubility of the polymer compared to the previously prepared polymers. ${ }^{[18,19]}$. Furthermore, the introducing1-phenethyl-4-piperidone ring as a polar group into the polymers chain gives rise to a slightly increased in the solubility process.

Table 2 Solubility characteristics of PAMEs VII

\begin{tabular}{cccccccccc}
\hline $\begin{array}{c}\text { Polymer } \\
\text { Number }\end{array}$ & DMF & DMSO & NMP & THF & $\mathrm{CH}_{3} \mathrm{Cl}$ & $\mathrm{CH}_{2} \mathrm{Cl}_{2}$ & $\mathrm{C}_{6} \mathrm{H}_{6}$ & $\mathrm{CH}_{3} \mathrm{OH}_{2}$ & $\mathrm{H}_{2} \mathrm{SO}_{4}$ \\
\hline $\mathrm{VII}_{\mathrm{a}}$ & ++ & ++ & + & + & - & + & - & - & ++ \\
$\mathrm{VII}_{\mathrm{b}}$ & ++ & ++ & + & + & - & + & - & - & ++ \\
$\mathrm{VII}_{\mathrm{c}}$ & ++ & ++ & ++ & ++ & + & ++ & + & + & ++ \\
$\mathrm{VII}_{\mathrm{d}}$ & ++ & ++ & ++ & ++ & + & ++ & + & + & ++ \\
\hline
\end{tabular}

$(++)$ Soluble at room temperature (RT); (+) Partially soluble at (RT); (-) Insoluble at (RT).

\subsubsection{Thermotropic behavior of PAMEs}

The thermotropic behavior of PAMEs VII a-d was determined using the DSC and OPM devices at the heating period. Having the DSC device several thermal transformations were applied, some of which were endothermic peaks and some exothermic peaks. The polymers $\mathrm{VII}_{\mathrm{a}-\mathrm{d}}$, display melt birefringence and stirred glimmering through OPM. Table 3 shows the phase transfer temperatures for the PAMEs and the isotropic phase of these polymers was observed in a temperature range of $233-357^{\circ} \mathrm{C}$ for the PAMEs VII ${ }_{\mathrm{a}-\mathrm{d}}$. In DSC studies, most of the polymers revealed multiple endothermic peaks by the heating traces of the PAMEs and that gave a glass-transition $(\mathrm{Tg})$ that was weak in the case of the polymer VII . The DSC profiles of the melting process of polymer $\mathrm{VII}_{\mathrm{b}}$ which revealed multiple endotherms at $123.00(\mathrm{Tg}), 204.91$ melting point $(\mathrm{Tm})$, 252.07 isotopic temperature $(\mathrm{Ti})$ and $399^{\circ} \mathrm{C}$, also probably with decomposition.

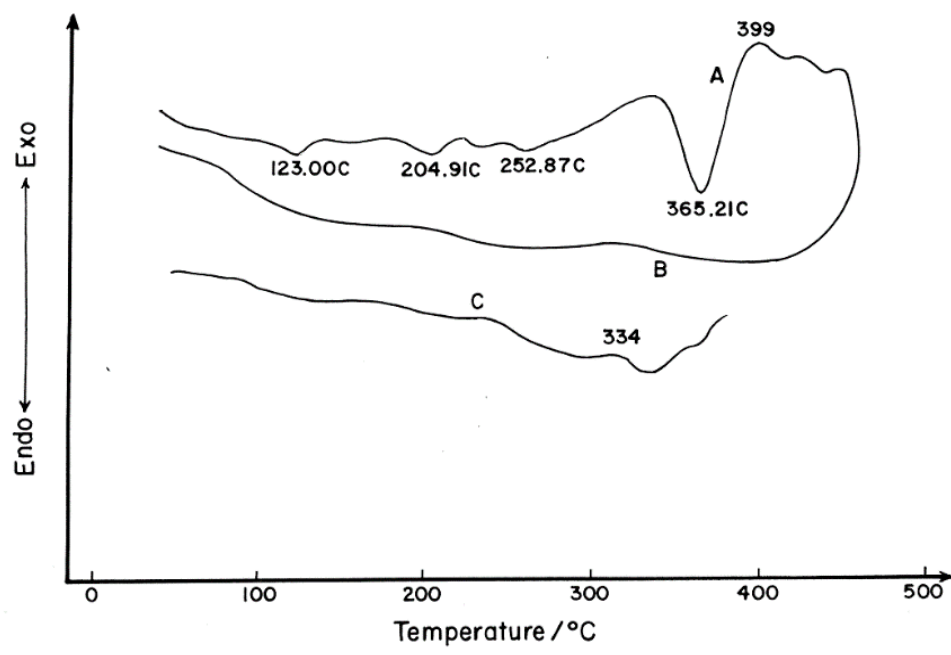

Figure 4 The DSC thermo gram of polymer $\mathrm{VII}_{\mathrm{b}}$.

When the polymer sample was cooled after preheating up to $450^{\circ} \mathrm{C}$, there were no exothermic or endothermic peaks. On a second heating cycle there was an endothermic at $334^{\circ} \mathrm{C}$. This phenomenon could be due to the presence of different transition temperatures ${ }^{[18,20]}$. The effect of spacer length on the thermal properties of the PAMEs VII a-d $_{\text {in }}$ shown in Table 3. It can also be clarified from (Table 3) that the Phase transition temperatures decrease when the 
methoxy groups are inserted with the elastic aliphatic spacer in the polymer core chain. ${ }^{[13,18]}$.

Table 3 Phase transition temperatures of PAMEs VII ${ }_{\text {a-d }}$.

\begin{tabular}{ccccccccc}
\hline $\begin{array}{c}\text { Polymer } \\
\text { number }\end{array}$ & $\mathrm{N}^{*}$ & Gave brightness & \multicolumn{3}{c}{$\begin{array}{c}\text { Tm and Ti } \\
\text { by (POM) }\end{array}$} & \multicolumn{4}{c}{$\begin{array}{c}\text { Tm and Ti } \\
\text { by(DSC) }\end{array}$} \\
\hline & & & $\mathrm{Tm}$ & $\mathrm{Ti}$ & $\Delta \mathrm{T}$ & $\mathrm{Tm}$ & $\mathrm{Ti}$ & $\Delta \mathrm{T}$ \\
$\mathrm{VII}_{\mathrm{a}}$ & 4 & Non & 213 & - & - & 215 & - & - \\
$\mathrm{VII}_{\mathrm{b}}$ & 6 & Yes & 202 & 248 & 46 & 204 & 252 & 48 \\
$\mathrm{VII}_{\mathrm{c}}$ & 8 & Yes & 208 & 241 & 33 & 210 & 245 & 35 \\
$\mathrm{VII}_{\mathrm{d}}$ & 10 & Yes & 190 & 233 & 43 & 190 & 230 & 40 \\
\hline
\end{tabular}

* Number of methylene units.

Thus, the unsubstituted para-linked PAMEs are infusible below its decomposition temperature. However it was found that the inclusion of the methoxy substituent in the solid aromatic ring as a mesogenic group reduces the glass transition temperature $(\mathrm{Tg})$, melting point $(\mathrm{Tm})$, and isotopic temperature (Ti). Moreover, the methoxy group controls the direction of the reactions that occur in the polymer structure during thermal transformations ${ }^{[24]}$. In the DSC measurements, the peaks are broad and sometimes sharp, due to the nature of the polymer construction, which creates interference in the various transformation

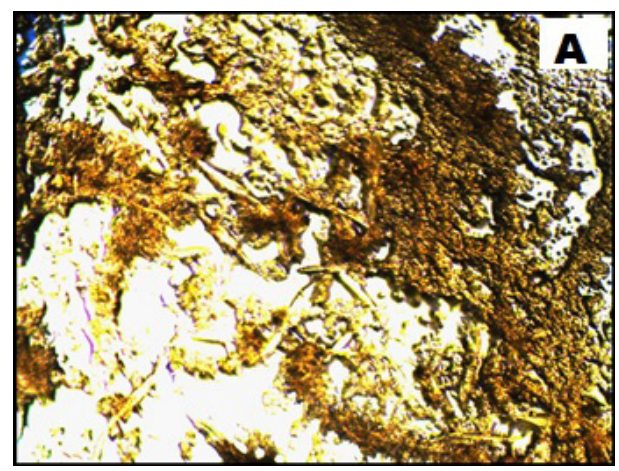

temperatures.

\subsubsection{Texture observation}

The behavior of polymer tissue at a certain temperature has been studied by quenching it in liquid nitrogen It appears that all PAMEs have a highly melt viscosity (with the exception of Polymer VII a indicating that the appearance of the nematic stage. Observation of the polymer $\mathrm{VII}_{\mathrm{b}}$ in the anisotropic melt displays nematic thread-like texture as shown in (figure 5) at $202^{\circ} \mathrm{C}(\mathrm{A})$ and (figure 5) at $248^{\circ} \mathrm{C}(\mathrm{Ti})(\mathrm{B})$. Similar nematic textures were observed for polymers $\mathrm{VII}_{\mathrm{c}, \mathrm{d}}$

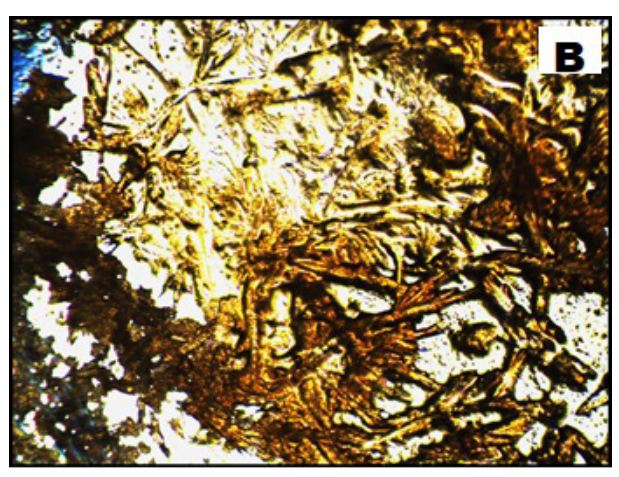

Figure 5 Photomicrographs of polymer $\mathrm{VII}_{\mathrm{b}}$, (A) at $202^{\circ} \mathrm{C}$ (before $\mathrm{Tm}$ ); (B) $248^{\circ} \mathrm{C}$ ( $\mathrm{Ti}$ ).

\section{Conclusions}

New chains of PAMEs which contain the piperidone moiety were prepared using the solution polymerization. Most of the polymers are found to be soluble in aprotic solvents and exhibit birefringence and glittering under polarized microscope. The Tm and Ti values increases as the length of the flexible methylene spacers are decreased and decrease with the introduction of the methoxy group as a substituent in the polymer core.

Author Contributions: The experiments were conducted by Amna A. Abayo and writing, paper discussion and revision was contributed by Ismail A. Alkskas, who was the corresponding author.

Conflict of Interest: No conflict of interest was reported by the authors.

\section{References}

[1] Grigoras M, Catanescu CO. Imine oligomers and polymers.
J Macromol Sci Part C. Polym Rev. 2004; 44:131-73.

[2] Tanaka H, Shibahara Y, Sato T, Ota T. Preparation and thermal behavior of spin polymers and their precursors based on azomethine mesogens. Eur Polym J. 1993;2:1525-30.

[3] Dutta PK, Jain P, Sen P, Trivedi R, Sen PK, Dutta J. Synthesis and characterization of a novel polyazomethine ether for NLO application. Eur Polym J .2003;39:1007-1011.

[4] Rahman MM, Hussein M A, Aly KI, Asiri AM. Thermally stable hybrid polyarylidene(azomethine-ether)s polymers (PAAP): an ultrasensitive arsenic(III) sensor approach Des Monomers Polym. 2018; 21(1): 82-98.

[5] Sana B, Koyilapu R, Dineshkumar S. High temperature PEMs developed from the blends of Polybenzimidazole and poly(azomethine-ether) Journal of Polymer Research. 2019; 26(2): 55.

[6] Yen H-J, Liou G-S. Novel blue and red electrochromic poly(azomethine ether)s based on electroactive 
triphenylamine moieties. Organic Electronics. 2010;11: 299-310.

[7] Shukla U, Rao KV, Rakshit AK. Thermotropic liquidcrystalline polymers: synthesis, characterization, and properties of poly(azomethine esters). J Appl Polym Sci. 2003;88:153-60.

[8] Sun S-J, Chang TC, Li CH. Synthesis and properties of thermotropic liquid crystalline poly(azomethinecarbonate)s. Eur Polym J .1993;29:951-955.

[9] Li C H, Chang T C. Synthesis and properties of poly(amideazomethine- ester). J Polym Sci Chem. 1991;29:361-367.

[10] Tanaka H, Shibahara Y, Sato T, Ota T. Preparation and thermal behavior of spin polymers and their precursors based on azomethine mesogens. Eur Polym J. 1993;2:1525-1530.

[11] Cozan V, Butuc E, Stoleriu A, Rusa M, Rusu M, Ni Y, Ding M. Poly(azomethine sulfones) with thermotropic liquid crystal-line behavior. J. Macromol. Sci., Pure Appl. Chem.1995;A32:1243-1262.

[12] Parks SB, Kim H, Zin WC, Jung, J C. Synthesis and properties of polyazomethines having flexible (n-alkyloxy)methyl side chains. Macromolecules. 1993;26:1627-1632.

[13] Hussein MA, Abdel-Rahman MA, Asiri AM, Alamry KA, Aly KI. Review on: liquid crystalline polyazomethines polymers. Basics, syntheses and characterization. Des Monomers Polym. 2012;15:431-463.

[14] Marin L, CozanV, Bruma M, Grigoras V C. Synthesis and thermal behaviour of new poly(azomethine-ether). Eur Polym J .2006;42: 1173-1182.

[15] Aly KI, Ahmed R A. Thermotropic liquid crystalline PAMEs containing cycloalkanone moiety in the polymer backbone. Liquid Crystals.2000; 27: 451-458.

[16] Aly KI, Khalaf AA, Alkaskas IA. Thermotropic liquid crystalline PAMEs containing dibenzylidene derivatives in the main chain. Eur Polym J. 2003;39:1035-1044.

[17] Kannan P , Raja S, Sakthivel P, Synthesis and characterization of thermotropic liquid crystalline poly(azomethine ether)s. Polymer.2004;45: 7895-7902

[18] Alkskas IA, El-Gnidi B Thermotropic LiquidCrystalline Poly(Azomethine-Ether)s Containing Dibenzylidene Derivatives in the Main Chain. J. Macromol. Sci. - Pure Appl. Chem 2006; 43:1435-1443.

[19] Aldred MP, Vlachos P, Dong D, Kitney SP, Tsoi WC, Neill MO. Heterocyclic reactive mesogens: synthesis, characterisation and mesomorphic behaviour. Liq Cryst. 2005;32:951-965.

[20] Ha, ST, Koh TM, Yeap GY, Lin HC, Lee SL, Win YF, Ong ST. Synthesis and mesomorphic properties of 6-methoxy-and 6-ethoxy-2-(2-hydroxy-4-alkanoyloxybenzylidenamino) benzothiazoles. Mol. Cryst. Liq. Cryst.2010; 528: 10-22.

[21] Aly KI, Abbady MA, Mahgoub SA, Hussein MA. Liquid crystalline polymers. IX. Main chainthermotropic poly (azomethine-ether)s containing thiazole moiety linked with polymethylenespacers. Journal of Express Polymer Letters. 2007;1:197-207.

[22] Kaya I, Avcı A, Kolcu F, Çulhaoğlu S. Synthesis, characterization, optical, and electrochemical properties of thermal stable novel PAMEs Designed Monomers \& Polymers. 2014;17(5): 481-490.

[23] Perrin DD, Armarigo WLF. Purification of laboratory chemicals. 3rd ed. New York: Pergamon Press; 1988.

[24] Demus D, Goodby J, Gray GW, Spiess H-W ,Vill V. Low molecular weight liquid crystals. In: Demus $D$, editor. Handbook of Liquid Crystals. 1st ed. 2B. Wiley-VCH; Weinheim, Germany: 1998. pp. 10-40. 